\title{
Eficácia social do Programa Minha Casa Minha Vida: discussão conceitual e reflexões a partir de um caso empírico*
}

\author{
Social effectiveness of the Minha Casa Minha Vida Program: \\ conceptual discussion and reflections based on an empirical case
}

Aline Werneck Barbosa Carvalho Italo Itamar Caixeiro Stephan

\section{Resumo}

Este artigo visa contribuir para o debate sobre a eficácia social de empreendimentos do Programa Minha Casa Minha Vida em cidades de pequena dimensão populacional e territorial, mediante análise dos conjuntos habitacionais implantados na cidade de Viçosa-MG. Os procedimentos metodológicos compreenderam levantamento de dados primários na Secretaria Municipal de Políticas Sociais, aplicação de questionários e observação direta nos conjuntos habitacionais estudados, além de dados secundários disponibilizados por órgãos governamentais e de pesquisa. Esses dados foram analisados com base nos indicadores de eficácia social elencados a partir da revisão de literatura. Concluiu-se pela ineficácia social dos empreendimentos, sobretudo devido às condições de infraestrutura, mobilidade urbana e acesso aos equipamentos de saúde, educação e lazer, fatores responsáveis pela segregação socioespacial dos residentes.

Palavras-chave: política habitacional; política habitacional brasileira; política habitacional em pequenas cidades; habitação de interesse social; Programa Minha Casa Minha Vida.

\begin{abstract}
This article aims to contribute to the debate on the social effectiveness of developments of the Minha Casa Minha Vida Program in small cities by analyzing housing estates built in the city of Viçosa (southeastern Brazil). The methodological procedures included primary data collection in the Municipal Department of Social Policies, administration of questionnaires and direct observation in the housing estates that were studied, as well as the analysis of secondary data provided by governmental and research agencies. These data were analyzed based on social effectiveness indicators listed from the literature review. It was concluded that the developments lack social effectiveness, mainly due to conditions related to infrastructure, urban mobility and access to health, education and leisure facilities, factors that are responsible for the socio-spatial segregation of residents.
\end{abstract}

Keywords: housing policy; Brazilian housing policy; housing policy in small cities; social housing; Minha Casa Minha Vida Program. 


\section{Introdução}

Este artigo tem como objetivo contribuir para o debate sobre a eficácia social dos empreendimentos habitacionais construídos por meio do Programa Minha Casa Minha Vida (PMCMV) em núcleos urbanos de pequena dimensão populacional e territorial, cujas dinâmicas urbanas - fundiárias e imobiliárias - são distintas daquelas próprias das grandes cidades e metrópoles.

Os processos decorrentes da implantação de conjuntos habitacionais do PMCMV nas grandes cidades têm sido objeto de estudo na área das Ciências Sociais e, mais especificamente, da Arquitetura e Urbanismo (Cardoso, 2013; Mendonça e Costa, 2011; Maricato, 2011; Hirata, 2011; Valença e Bonates, 2010, entre outros, além de numerosas teses e dissertações sobre o tema). Entretanto, ainda falta uma visão abrangente dos resultados do Programa nas demais unidades locais, que conformam o maior número e a maior extensão do território brasileiro. Referindo-se aos efeitos territoriais do PMCMV, Cardoso (2013, p. 15) assinala que "(..) há ainda muitos pontos a serem aprofundados e que certamente exigirão maiores esforços de pesquisa e de reflexão".

Com esse foco, procurou-se descrever os empreendimentos do PMCMV implantados na cidade de Viçosa-MG e o perfil da população neles residente, com a finalidade de estabelecer relações entre as características físicas e a satisfação dos moradores, e compreender a eficácia social desse Programa no município.

Para tanto, foi realizada pesquisa descritiva, com abordagem qualitativa e quantitativa, apoiada em dados primários e secundários.
A coleta de dados primários compreendeu o levantamento das fichas de cadastramento dos beneficiários do PMCMV arquivadas no Departamento de Habitação da Secretaria de Políticas Sociais do município de Viçosa, a aplicação de questionários e a observação direta do comportamento dos moradores nos conjuntos habitacionais estudados, registrados por meio de levantamento fotográfico e anotações de campo. A observação direta e o levantamento fotográfico dos conjuntos foram feitos concomitantemente à visita destinada à aplicação dos questionários. As visitas ocorreram nos meses de junho a dezembro de 2014. Foram aplicados 110 questionários abrangendo os três empreendimentos, o que correspondeu a um erro amostral de 7,8\% com $95 \%$ de nível de confiança. Já os dados secundários se originaram de pesquisa em documentos e dados oficiais disponibilizados publicamente por órgãos governamentais e de pesquisa, como o Ministério das Cidades, IBGE e Prefeitura Municipal de Viçosa. A coleta desses dados compreendeu o levantamento dos projetos arquitetônicos dos empreendimentos no Instituto de Planejamento Municipal - Iplam e consulta a relatórios e outros documentos na Secretaria Municipal de Políticas Sociais. Por fim, os dados coletados foram tabulados e analisados com base nos indicadores de eficácia social elencados a partir da revisão de literatura.

Com a finalidade de realizar uma reflexão acerca dos resultados encontrados, este artigo foi estruturado em duas grandes partes. Na primeira, empreendeu-se uma discussão conceitual sobre os dois principais temas que fundamentam a posterior análise empírica: os impactos do Programa Minha Casa Minha Vida apontados pela literatura e o conceito de 
eficácia social, importante indicador utilizado na avaliação de políticas públicas. Na segunda parte, realizou-se uma reflexão acerca da eficácia social do Programa nos três empreendimentos que constituem o objeto empírico deste artigo: os conjuntos Benjamin José Cardoso, César Santana Filho e Floresta.

\section{Discussão conceitual}

\section{PMCMV no contexto da política habitacional brasileira}

O Programa Minha Casa Minha Vida deve ser compreendido num contexto mais amplo, econômico e político, que caracteriza a política habitacional brasileira e o cenário internacional a partir da década de 1990.

Do ponto de vista da habitação de interesse social, o período que se estende de 1988 - quando entra em vigor a atual Constituição Federal - até 2003, quando se cria o Ministério das Cidades, é marcado pelo vazio deixado pela extinção do Banco Nacional de Habitação - BNH e pela ausência de uma estrutura de âmbito federal organizada para a condução das políticas urbana e habitacional.

Em meados da década de 1990, sob forte influência das políticas de recorte neoliberal, inicia-se um processo de estímulo ao mercado imobiliário para a produção de moradias voltadas para as classes média e média-alta, mediante a aprovação de importantes marcos institucionais e de instrumentos financeiros, capazes de garantir a segurança de investidores no setor habitacional (Shimbo, 2011; Cardoso e Aragão, 2011).
Assim, no final do governo Fernando Henrique Cardoso (1995-2002) e no primeiro governo do ex-presidente Luís Inácio Lula da Silva (2003-2006), foi se configurando um contexto favorável à participação do setor privado na promoção habitacional. A estabilidade macroeconômica do país a partir do final da década de 1990, com o Plano Real, e as novas orientações na política econômica a partir do governo Lula, devido especialmente à redução das taxas de juros, alteraram o interesse dos investidores e de agentes financeiros em relação à construção civil e ao mercado imobiliário.

No âmbito da habitação de interesse social, em 2003, já no governo do ex-presidente Lula, começaram a ser implementadas mudanças no quadro geral que caracterizava a situação institucional da política habitacional. Criou-se o Ministério das Cidades, que passou a ser o órgão responsável pela Política de Desenvolvimento Urbano e pela Política de Habitação, ampliando-se os investimentos nos setores da habitação e adequando-se os programas existentes às características do déficit habitacional e de infraestrutura urbana.

0 período que se seguiu à criação do Ministério das Cidades foi marcado pela retomada do planejamento estatal no setor habitacional e urbano, bem como pelo aumento do volume de recursos e subsídios para a habitação de interesse social (Denaldi, 2012; Buonfiglio e Bastos, 2011). Em 2004 aprovou-se a Política Nacional de Habitação e o Sistema Nacional de Habitação (SNH) e, em 2005, o Sistema Nacional de Habitação de Interesse Social (SNHIS) e o Fundo Nacional de Habitação de Interesse Social (FNHIS), com o objetivo de garantir que os recursos públicos sejam destinados exclusivamente a subsidiar a população de mais baixa renda (Brasil, 2005). 
Concomitantemente, a partir de 2004, foram criadas várias medidas com o objetivo de dar segurança jurídica e econômica ao mercado privado de imóveis e estimular o setor da construção civil. Nessa época teve origem um processo de financeirização imobiliária, mediante a abertura do capital de empresas de construção civil na Bolsa de Valores. Essas empresas lastrearam seus papéis em estoque de terras e lançamentos imobiliários, obtendo vultosos lucros.

Entretanto, esse contexto é alterado pela crise econômica mundial que se inicia nos Estados Unidos em 2008. Diante do novo quadro, o governo brasileiro decide adotar medidas de expansão de crédito e apoio aos setores que se encontravam em dificuldades, dentre eles o setor imobiliário. Para continuar expandindo o mercado habitacional, lança o Programa Minha Casa Minha Vida - PMCMV (Cardoso e Aragão, 2011).

Instituído pela Lei n. 11.977, de 7 de juIho de 2009, o PMCMV constitui, atualmente, o principal programa habitacional do governo federal, cujo objetivo consiste na construção maciça de moradias visando à melhoria do sistema habitacional para a população de baixa e média renda. No âmbito do PMCMV estão previstos dois subprogramas: o PNHU - Programa Nacional de Habitação Urbana e o PNHR - Programa Nacional de Habitação Rural. O PNHU "tem por objetivo promover a produção ou aquisição de novas unidades habitacionais ou a requalificação de imóveis urbanos" (Art. $4^{\circ}$, Lei n. 12.124/2011), enquanto cabe ao PNHR "subsidiar a produção ou reforma de imóveis aos agricultores familiares e trabalhadores rurais (...)" (Art. 11, Lei n. 12.124/2011), nas propriedades rurais, posses e agrovilas.
Apesar de ser criado como medida anticíclica para fazer frente à crise econômica, o PMCMV representou uma política social de grande escala, que estimulou a criação de empregos e de investimentos no setor da construção civil, atendendo à demanda habitacional de baixa renda que o mercado por si só não alcançava até então (Arantes e Fix, 2009; Hirata, 2011; Klintowitz, 2011).

Amplamente implementado a partir do ano de 2010, a meta inicial do PMCMV era a construção de 1 milhão de moradias na área urbana, sendo 400 mil destinadas a beneficiários com renda familiar até 3 salários mínimos, para a qual está previsto subsídio integral, e o restante para famílias inseridas em duas faixas de renda ( 3 a 6 e 6 a 10 salários mínimos), correspondendo a cada uma delas um tipo de modalidade de financiamento de produção da habitação. Lançada a segunda versão do Programa, pela Lei $n$. 12.1214/2011, estabeleceu-se como nova meta a construção de 2 milhões de moradias na área urbana, até 2014.

Na primeira fase do Programa, que corresponde aos anos de 2009 e 2010, foram contratadas 1,005 milhão de moradias. Já na segunda fase, que começou em 2011, foram contratadas 2,385 milhões de unidades. Os dados referentes ao programa em julho de 2013 eram da ordem de 3.012.848 unidades contratadas e, até julho de 2014, o Governo Federal havia entregue 1,7 milhão de moradias, beneficiando 6,4 milhões de pessoas e totalizando um investimento de $\mathrm{R} \$ 361,6$ bilhões, ${ }^{1}$ dos quais $60 \%$ voltaram-se para a menor faixa de renda, o que indica o direcionamento do programa para a população de menor poder aquisitivo. 
A despeito desses vultosos resultados quantitativos, vários pesquisadores têm apontado a má qualidade da produção habitacional do Programa, bem como a localização periférica dos empreendimentos, ditada na maioria das vezes por interesses especulativos do mercado de terras (Maricato, 2012; Rolnik e Klink, 2011; Penalva e Duarte, 2010; Hirata, 2009; Bonduki, 2009).

Autores como Shimbo (2011), Cardoso e Aragão (2011) e Valença e Bonates (2010) apontam que a política habitacional no Brasil, a partir dos anos 1990, tem procurado consolidar instrumentos financeiros alinhados com os mercados globais, reestruturando a maneira de os interesses privados operarem no sistema, entretanto têm fracassado em relação aos resultados sociais.

Ao mesmo tempo em que se assiste a um salto qualitativo na forma de gerir o tema moradia a partir da criação do Ministério das Cidades e de instrumentos como a Política Nacional de Habitação, o SNHIS e o FNHIS, do ponto de vista da produção de cidade, vários estudos têm demonstrado a permanência dos mesmos cenários urbanos e efeitos socioespaciais, onde a periferia absorve a moradia popular advinda do PMCMV, em regiões desprovidas de infraestrutura e serviços urbanos adequados (Silva e Silva, 2013; Maricato, 2009).

Entretanto, a maioria desses estudos volta-se para as metrópoles e cidades médias, enquanto pouco tem sido investigado sobre a eficácia social do PMCMV nas pequenas cidades, que constituem a grande maioria das unidades locais no Brasil. ${ }^{2}$

\section{0 conceito de eficácia social de uma política urbana}

A implantação da habitação de interesse social sem a devida preocupação com o meio é uma tendência no cenário das cidades brasileiras, cujo resultado é a exclusão da camada de baixa renda dos locais privilegiados na cidade, devido ao interesse privado. A literatura na área de Arquitetura, Urbanismo e Planejamento Urbano mostram que se torna cada vez mais comum a construção de conjuntos habitacionais afastados desses locais e, em muitos casos, distantes de equipamentos e serviços coletivos e de uso social, o que gera desperdícios.

Os efeitos sociais e territoriais das políticas habitacionais podem ser medidos a partir de metodologias de avaliação de políticas sociais. A avaliação é um instrumento central e indispensável para a compreensão do sucesso e do fracasso das políticas públicas, constituindo-se como importante ferramenta de gestão (Marinho e Façanha, 2001, p. 1).

Referindo-se à avaliação de políticas e programas sociais, Cotta $(1998$, p. 107) ressalta que "(...) a avaliação desempenha um papel central no esforço de racionalização dos programas e projetos sociais. A ausência de controles e de metodologias de avaliação geralmente leva a um gasto social ineficiente e, consequentemente, ao desperdício dos recursos disponíveis".

A avaliação pode ocorrer em todas as fases do ciclo de desenvolvimento de uma política (policy cicle): fase de formulação, implementação e controle dos impactos. Essa última 
fase "(...) é imprescindível para o desenvolvimento e a adaptação contínua das formas e instrumentos de ação pública". Nela se "(..) apreciam os programas já implementados no que diz respeito aos seus impactos efetivos. Investigam-se os déficits de impacto e os efeitos colaterais indesejados para poder extrair consequências para ações e programas futuros" (Trevisan e Van Bellen, 2008, p. 531). Nela se apreciam os impactos efetivos dos programas já implementados, investigando-se "(...) os déficits de impacto e os efeitos colaterais indesejados para poder extrair consequências para ações e programas futuros" (ibid, p. 531).

Conforme Carvalho (2003, p. 186), a avaliação de impacto "é aquela que focaliza os efeitos ou impactos produzidos sobre a sociedade e, portanto, para além dos beneficiários diretos da intervenção pública, avaliando-se sua efetividade social".

Embora não haja consenso quanto aos aspectos metodológicos e conceituais da avaliação de políticas, a literatura especializada costuma propor a avaliação de políticas e programas em termos de sua eficácia, eficiência e efetividade ${ }^{3}$ (Trevisan e Van Bellen, 2008; Monteiro, 2002; Jannuzzi, 2002; Marinho e Façanha, 2001; Aguillar e Ander-Egg, 1994).

Segundo Marinho e Façanha (2001, p. 2), "(...) a efetividade diz respeito à capacidade de se promover resultados pretendidos; a eficiência denotaria competência para se produzir resultados com dispêndio mínimo de recursos e esforços; e a eficácia, por sua vez, remete a condições controladas e a resultados desejados de experimentos (...)". A escolha desses critérios depende do que se deseja privilegiar na avaliação.
Para os autores acima citados, os programas sociais devem ser avaliados por critérios de eficácia, "uma vez que, esperadamente, os investimentos que mobilizam devem produzir os efeitos desejados" (ibid., p. 7).

Essa posição é corroborada por outros autores. Jannuzzi (2002) considera que na avaliação dos programas implementados, os resultados devem ser aferidos através de "indicadores-produto" de diferentes tipos, "para medir a eficácia no cumprimento das metas específicas e a efetividade social das soluções sugeridas" (p. 61). Trevisan e Van Bellen (2008) também sugerem o uso do indicador de eficácia nas avaliações posteriores à implementação de programas (avaliação ex-post ou somativa), que visam trabalhar com impactos e processos. De modo geral, a eficácia é utilizada como critério para avaliar o alcance dos objetivos e metas das políticas ou programas, representando, como ressalta Chiechelski (2005, p. 4), "uma medida de aproximação ou distanciamento entre os objetivos/metas previstos e os resultados efetivamente praticados".

Para Fagundes e Moura (2009, p. 99), a avaliação de eficácia é entendida como "uma avaliação da relação entre os objetivos e instrumentos explícitos de um dado programa", porém, isso "não significa apenas aferir o alcance das metas propostas por um programa ou política", mas também avaliar os efeitos indiretos resultantes da intervenção, sejam eles relacionados ou contrários à intencionalidade da ação.

Nessa mesma linha, Monteiro (2002, p. 2) aponta que "(..) a análise de impacto vai se interessar pelas consequências, previstas ou imprevistas, que um determinado programa de 
governo poderá ter sobre um grupo social". 0 foco no impacto da ação governamental leva o avaliador ao contato da realidade social "para investigar em que medida aquela realidade sofreu alguma efetiva mudança" (p. 2). Citando Mohr (1995, p. 4), o autor completa dizendo que "o impacto de um programa pode ser entendido como o resultado de uma comparação entre aquilo que ocorreu após a implementação do programa e aquilo que teria acontecido se o programa não tivesse sido implementado". Dessa forma, seria possível identificar "se os indivíduos estão em melhor situação por causa desta atividade governamental do que estariam sem ela" (Monteiro, 2002, p. 2).

Essa perspectiva de comparação entre uma situação anterior e posterior à implantação de uma política é também considerada por Marinho e Façanha (2001) e Ramos e Sá (2002). Referindo-se especificamente à avaliação de políticas urbanas e habitacionais, Ramos e Sá (2002) consideram que a mensuração do grau de eficácia social associa-se a "variáveis que caracterizam a estrutura produtiva do território municipal, em particular à localidade onde o conjunto está situado, e à sua posição em comparação com as demais áreas do município e com a área onde sua população anteriormente se fixara" (p. 164). A partir desse conceito, a avaliação do grau de eficácia social deve abranger um amplo conjunto de variáveis, dentre elas: a classe-alvo da política (população atendida, segundo os níveis de renda, escolaridade, emprego e procedência); o conteúdo, grau de formalização e acompanhamento dos projetos da política de habitação popular; o padrão das casas do conjunto habitacional em relação ao padrão das residências ocupadas anteriormente pelas famílias; o padrão das residências circunvizinhas e das residências das demais localidades/bairros do município; a distância entre o conjunto habitacional e os locais de trabalho dos seus moradores; o padrão de infraestrutura (água, esgoto, luz, drenagem, pavimentação e arborização) do conjunto habitacional em relação ao padrão de infraestrutura na localidade de residência anterior das famílias; a existência de equipamentos e serviços coletivos, no espaço do conjunto habitacional ou nas suas imediações, comparado com o que existia nos bairros onde sua população residia anteriormente; as condições socioeconômicas dos moradores antes e depois da ocupação do conjunto habitacional; e, por fim, a satisfação dos moradores quanto às condições da moradia em seu conjunto, em relação às quais estavam anteriormente submetidos (Ramos e Sá, 2002, pp. 164-167). Portanto, a medida da eficácia social vai indicar se a condição existente no conjunto habitacional é melhor, pior ou semeIhante àquela vivenciada pelo beneficiário no seu bairro de origem.

Por sua afinidade com os critérios de avaliação anteriormente expostos e por sua aderência à questão específica da habitação de interesse social, optou-se por adotar o critério comparativo proposto por Ramos e Sá (2002) para a avaliação da eficácia social da implantação do PMCMV em Viçosa. 


\section{Reflexões a partir de um caso empírico}

\section{O Programa Minha Casa Minha Vida em Viçosa}

0 município de Viçosa localiza-se na Zona da Mata mineira. Ocupa área de $300,15 \mathrm{~km}^{2}$ e tem 72.220 habitantes, sendo 56.445 residentes na área urbana, o que representava $78,17 \%$ da população, em 2010 (IBGE, 2010). Entretanto, a população flutuante, ${ }^{4}$ constituída principalmente por estudantes, imprime à cidade uma dinâmica imobiliária que a distingue das demais cidades de mesmo porte populacional.

A economia local gira em torno das atividades da Universidade Federal de Viçosa e de outras universidades e faculdades implantadas no município, e, consequentemente, das demandas, necessidades, padrão financeiro, hábitos e gostos dos estudantes, professores e funcionários universitários. Impulsionada principalmente pelo mercado imobiliário e pelo setor de serviços, a cidade enfrenta uma série de problemas, como a especulação imobiliária, que reorganiza a distribuição da população e reconfigura a paisagem urbana, e a desigualdade social, expressa nas características morfológicas dos bairros periféricos e de suas tipologias habitacionais.

A partir da década de 1970, a cidade passou por um processo de rápida urbanização, motivado principalmente pela expansão das atividades da Universidade Federal de Viçosa. A elevada demanda por moradia estudantil e a oferta limitada de terrenos na zona central têm estimulado a especulação imobiliária, que eleva os preços dos lotes e produz um processo acelerado de verticalização no Centro da cidade (Paula, 2013). Embora o município disponha de Plano Diretor e legislação urbanística atualizada de controle do uso e ocupação do solo, ${ }^{5}$ a falta de atuação mais decisiva do poder público municipal sobre o mercado imobiliário tem resultado num padrão de ocupação que concentra a população mais abastada nas áreas centrais e servidas por infraestrutura, enquanto os bairros destinados à população de menor renda crescem em direção às encostas, ocupando áreas de relevo muito acidentado ou em direção às porções mais distantes da mancha urbana.

Dados da Fundação João Pinheiro, referentes ao ano 2010, indicaram um déficit habitacional básico de 2.023 unidades, correspondendo a $8,9 \%$ do total de domicílios do município, dos quais 1.339 conformam o déficit habitacional na faixa de renda até três salários mínimos, ou seja, $66,18 \%$ do déficit total. A maior porcentagem do déficit $(46,05 \%)$ corresponde a domicílios com ônus excessivo de aluguel, 43,51\% à situação de coabitação familiar e apenas $5,54 \%$ corresponde a domicílios precários. Um montante de 2.339 domicílios urbanos tem algum tipo de inadequação habitacional: 1.347 (57,6\%) não têm rede de esgotamento sanitário, 817 (34,9\%) não têm rede de abastecimento de água e $317(13,5 \%)$ não descartam o lixo corretamente (Fundação João Pinheiro, 2013).

Apesar desse quadro, pode-se dizer que a produção de moradia para a população de baixa renda foi inserida na agenda das políticas públicas em Viçosa apenas a partir de 2010, com a contratação de unidades habitacionais pelo PMCMV. Antes disso, houve algumas ações esporádicas, provenientes de iniciativas 
isoladas da administração municipal ou de entidades da sociedade civil organizada.

A partir da aprovação do Plano Diretor, em 2000, o gerenciamento do setor de habitação em Viçosa ficou a cargo de três órgãos municipais: a Secretaria de Assistência Social, cujo Departamento de Habitação e Urbanismo é responsável por gerenciar o PMCMV ou outros programas habitacionais; o Conselho Gestor do Fundo de Habitação de Interesse Social (CGHIS), a quem cabe o estabelecimento de diretrizes e critérios para a priorização de linhas de ação e alocação de recursos do Fundo de Habitação de Interesse Social (FHIS); e o Instituto de Planejamento Municipal (Iplam), encarregado da elaboração e execução da política urbana do município e de sua articulação com a política habitacional.

No período compreendido entre 2011 e 2014, foram implantados três conjuntos habitacionais do PMCMV para atender a população com renda inferior a três salários mínimos: Benjamim José Cardoso, César Santana Filho e Floresta.

0 conjunto Benjamim José Cardoso (conhecido como "Coelha") foi o primeiro empreendimento do PCMV construído na cidade. Entregue em setembro de 2011, localiza-se próximo ao Bairro Santa Clara e tem 132 unidades habitacionais unifamiliares implantadas em lotes de $10 \mathrm{~m} \times 13 \mathrm{~m}$. Os outros dois conjuntos foram concluídos e entregues em 2012. 0 conjunto habitacional Floresta é um condomínio vertical, constituído por 80 unidades habitacionais reunidas em cinco edifícios de quatro pavimentos.0 conjunto César Santana Filho (também chamado de Sol Nascente) foi o terceiro empreendimento entregue à população; está localizado a $500 \mathrm{~m}$ do Conjunto
Benjamin José Cardoso e conta com 123 casas, localizadas em lotes de $10 \mathrm{~m}$ x 15m (Figuras 1 e 2).

Como se pode observar, são empreendimentos de reduzidas dimensões, com um pequeno número de unidades habitacionais. As casas e apartamentos têm em média 39 m2 e têm sala, dois quartos, banheiro, área de serviço e cozinha. 0 padrão construtivo e de acabamento segue rigorosamente o prescrito pelas especificações do Programa, sendo construídos em alvenaria estrutural.

Os conjuntos Benjamin José Cardoso e César Santana Filho localizam-se a cerca de 1,5 km do centro da cidade, porém o relevo muito acidentado e as más condições de infraestrutura da via de acesso (calçamento em pé de moleque e falta de calçadas) dificultam a acessibilidade dos pedestres e do transporte coletivo. 0 acesso principal é feito, então, por um caminho alternativo, que amplia a distância e o tempo de percurso, além das condições precárias de um trecho da via principal próxima aos empreendimentos, que não tem calçamento, calçadas, nem iluminação pública. A falta desses recursos é grave, principalmente em períodos de chuva, pois impossibilita o tráfego do ônibus escolar, que é responsável pelo transporte de crianças e adolescentes até as instituições de ensino. Nas suas proximidades não há equipamentos urbanos como escolas, creches e estabelecimentos de atendimento básico à saúde (Unidade Básica de Saúde), e o comércio restringe-se a um bar. 0 serviço de Correio foi recentemente instalado, mas os moradores reclamam que não há telefone público nem telefonia fixa, o sinal de telefone celular é fraco e irregular, os horários de ônibus são insuficientes e a principal via de acesso aos 
Figura 1 - Localização dos habitacionais Benjamin José Cardoso (Coelha), César Santana Filho (Sol Nascente) e Floresta - Viçosa, MG, 2011

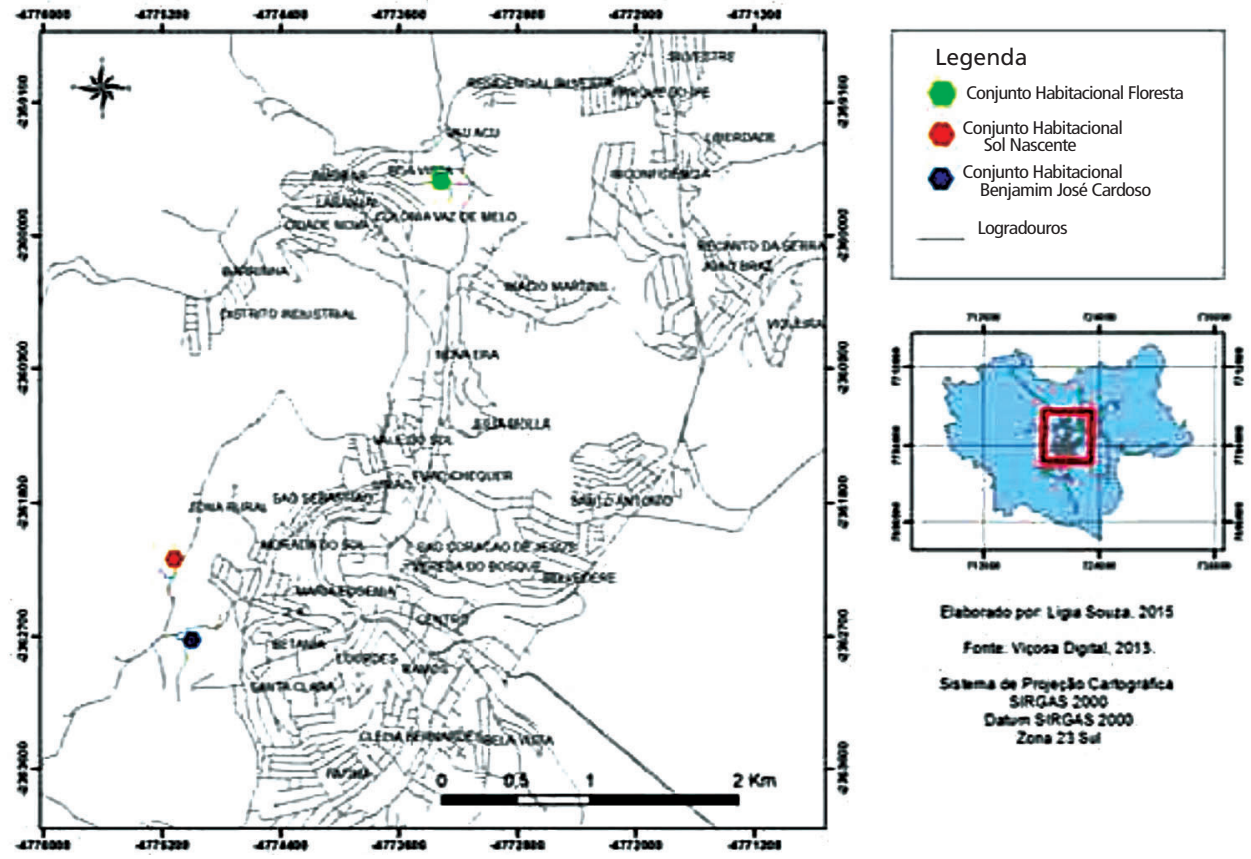

Fonte: Acervo dos pesquisadores.

Figura 2 - Vista dos conjuntos habitacionais: a) Benjamin José Cardoso;

b) Floresta. Viçosa; c) César Santana Filho - Viçosa, MG, 2011

a)

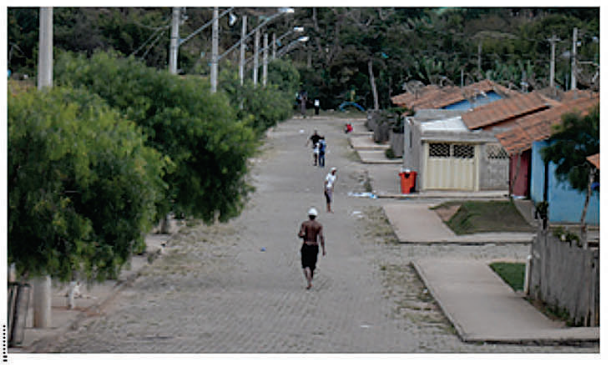

b)

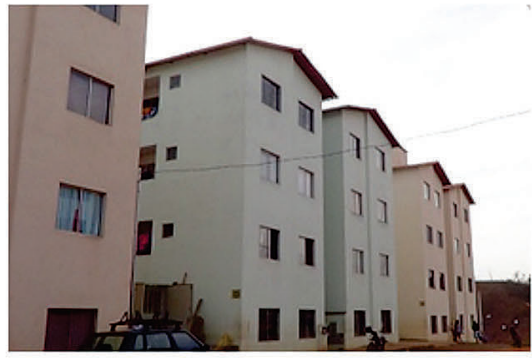

c)

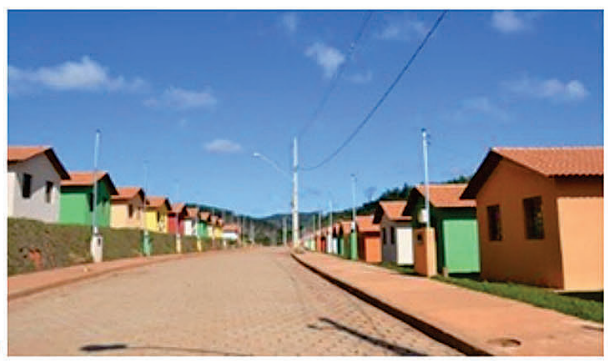

Fonte: Acervo dos pesquisadores. 
conjuntos residenciais ainda não foi pavimentada. A mesma situação de relevo acidentado repete-se no Condomínio Floresta, embora as condições de acessibilidade sejam melhores e haja equipamentos sociais e estabelecimentos comerciais nas suas proximidades.

Os três conjuntos foram produzidos por empresas locais, de pequeno porte, que se encarregaram de todo o processo de provisão habitacional, desde a escolha e compra do terreno até a incorporação e construção das unidades, cabendo ainda às empresas a correção de eventuais problemas construtivos, pelo prazo de cinco anos.

Ao poder público municipal couberam a realização do cadastro dos interessados e a organização dos documentos para serem enviados à Caixa Econômica Federal, visando à seleção final dos beneficiários, o que foi feito no âmbito do Departamento de Habitação da Secretaria Municipal de Políticas Sociais. Também ficaram a cargo do município a aprovação dos projetos e a contrapartida exigida pelo Programa, que se deu sob a forma de implantação da infraestrutura de serviços urbanos nas vias de acesso aos empreendimentos, já que o município não tem banco de terras.

A construção dos empreendimentos ocorreu durante o processo de elaboração do Plano Local de Interesse Social (PLHIS), deslocando o foco das discussões em torno da implantação de um processo permanente de planejamento habitacional no município. 0 Conselho Municipal de Habitação de Interesse Social (CGHIS) teve papel secundário no processo, responsabilizando-se apenas pela elaboração de critérios para seleção dos beneficiários. Assim sendo, 0 município deixou de exercer um importante papel na localização dos conjuntos habitacionais, que foram construídos em áreas mal servidas por equipamentos urbanos comunitários, sobretudo nos conjuntos Benjamin José Cardoso e César Santana Filho.

\section{A eficácia social do Programa Minha Casa Minha Vida em Viçosa}

Adotando como referência o método de avaliação da eficácia social proposto por Ramos e Sá (2002), foram analisadas variáveis que caracterizam a localidade onde o conjunto habitacional está situado em comparação com a área onde sua população anteriormente se fixara. Os resultados da avaliação foram obtidos a partir de dados obtidos na Secretaria Municipal de Políticas Sociais, dos questionários aplicados aos moradores e da observação direta realizada nos três conjuntos habitacionais.

As variáveis utilizadas para a avaliação do Programa foram agrupadas em cinco dimensões, quais sejam: focalização do empreendimento, interação social, segregação social, segregação espacial e satisfação com a moradia.

\section{a) Focalização do Programa}

Essa dimensão refere-se ao público-alvo da política e visa avaliar se os empreendimentos atendem à classe social para o qual o Programa foi implantado. As principais características sociais e econômicas das famílias residentes nos três conjuntos habitacionais foram sintetizadas na Tabela 1. 
Tabela 1 - Perfil socioeconômico das famílias residentes nos conjuntos habitacionais Benjamin José Cardoso (BJC), César Santana Filho (CSF) e Floresta Viçosa-MG (2014)

\begin{tabular}{|c|c|c|c|c|}
\hline \multicolumn{2}{|c|}{ Caracterização das famílias } & BJC & CSF & Floresta \\
\hline Sexo do proprietário & Feminino & 91,3 & 78,9 & 81,3 \\
\hline $\begin{array}{l}\text { Faixa etária dos } \\
\text { proprietários }\end{array}$ & $\begin{array}{l}17 \text { (emancipado) } \\
18 \text { a } 20 \text { anos } \\
20 \text { a } 45 \text { anos } \\
>45 \text { anos }\end{array}$ & $\begin{array}{r}0 \\
1,6 \\
72,4 \\
26,0\end{array}$ & $\begin{array}{r}0,8 \\
4,1 \\
71,5 \\
23,6\end{array}$ & $\begin{array}{r}0 \\
3,8 \\
72,5 \\
23,7\end{array}$ \\
\hline $\begin{array}{l}\text { Estado civil } \\
\text { dos proprietários }\end{array}$ & $\begin{array}{l}\text { Casado + união estável } \\
\text { Solteiro }\end{array}$ & $\begin{array}{l}33,4 \\
46,8\end{array}$ & $\begin{array}{l}25,2 \\
41,4\end{array}$ & $\begin{array}{l}42,5 \\
30,0\end{array}$ \\
\hline Número de filhos & $\begin{array}{l}\text { Até } 3 \text { filhos } \\
4 \text { e } 5 \text { filhos } \\
6 \text { filhos ou mais }\end{array}$ & $\begin{array}{r}76,5 \\
18,5 \\
5,0 \\
\end{array}$ & $\begin{array}{r}75,7 \\
17,4 \\
6,9 \\
\end{array}$ & $\begin{array}{r}76,0 \\
17,7 \\
6,3\end{array}$ \\
\hline $\begin{array}{l}\text { Família com pessoas } \\
\text { com deficiência }\end{array}$ & $\begin{array}{l}\text { Geral } \\
\text { Usuário de cadeira de rodas }\end{array}$ & $\begin{array}{l}2,4 \\
0,8\end{array}$ & $\begin{array}{l}9,8 \\
0,8\end{array}$ & $\begin{array}{r}10,0 \\
0,0\end{array}$ \\
\hline Renda familiar & $\begin{array}{l}\text { Até } 3 \mathrm{SM} \\
\text { Até } 1 \mathrm{SM}\end{array}$ & $\begin{array}{r}100,0 \\
66,9\end{array}$ & $\begin{array}{r}100,0 \\
63,4\end{array}$ & $\begin{array}{r}100,0 \\
63,8\end{array}$ \\
\hline Benefício do governo & Sim & 62,7 & 59,4 & 63,8 \\
\hline $\begin{array}{l}\text { Condições de propriedade } \\
\text { da moradia anterior* }\end{array}$ & $\begin{array}{l}\text { Imóvel alugado } \\
\text { Imóvel cedido/coabitação } \\
\text { Barraco/cortiço } \\
\text { Próprio } \\
\text { Imóvel em área de risco pela Defesa Civil }\end{array}$ & $\begin{array}{r}66,9 \\
32,3 \\
0 \\
0,8 \\
0,8\end{array}$ & $\begin{array}{r}56,9 \\
37,4 \\
3,3 \\
0 \\
2,4\end{array}$ & $\begin{array}{r}66,2 \\
28,8 \\
3,7 \\
0 \\
1,3\end{array}$ \\
\hline
\end{tabular}

* Obs.: Existem imóveis alugados e/ou em coabitação que estão em área de risco. Fonte: Resultados da pesquisa.

Os beneficiários dos três conjuntos habitacionais têm características sociais bastante semelhantes. A maioria dos proprietários são mulheres, conforme recomendado pelas diretrizes do PMCMV, e constituem-se como famílias jovens (cujos chefes têm entre 20 e 45 anos), o que sugere que ainda podem ter um longo tempo de moradia no conjunto, podendo vir a constituir futuros laços de solidariedade com os vizinhos e sentimentos de pertencimento ao lugar. Também chama atenção o significativo percentual de famílias cujos chefes são solteiros, superando o percentual de formatos familiares nucleares (casados + união estável) nos conjuntos habitacionais Benjamin José Cardoso e César Santana Filho. A maior parte tem no máximo tem filhos, o que é um indicativo de predominância de famílias pequenas ou médias. Esse resultado poderia justificar, de certa forma, a existência de apenas dois quartos nas residências, porém a construção de mais um quarto sobressaiu nas entrevistas como um dos principais desejos de reforma dos moradores nos conjuntos Benjamin José Cardoso e César Santana Filho. Outro resultado importante, embora o percentual seja pequeno, é a existência de famílias com seis filhos ou mais, pois isso representa mais de três pessoas por dormitório, 
caracterizando inadequação habitacional por adensamento, dado importante diante da avaliação da eficácia social do programa. Embora também seja pequeno o número de pessoas com deficiência, deveria ter sido previsto um percentual de unidades adaptadas a pessoas com necessidades especiais.

Antes de se mudar para os conjuntos habitacionais, a maioria das famílias residia em imóveis alugados, sobressaindo também o percentual de moradores do conjunto César Santana Filho que viviam anteriormente em condição de coabitação.

Por fim, todos os beneficiários percebem no máximo 3 salários mínimos, nos três conjuntos habitacionais investigados. Mais do que isso, chama a atenção o elevado percentual de beneficiários cuja renda familiar não excede 1 salário mínimo e que recebem benefício do governo, na maioria das vezes na forma do Programa Bolsa Família.

Esses resultados indicam a clara focalização do Programa no município.

b) Interação social

A interação social foi avaliada a partir dos seguintes indicadores: relação com os vizinhos do conjunto habitacional e do entorno, espaço de convívio e espaços de lazer para as crianças (Tabela 2).

Tabela 2 - Percepção dos moradores dos conjuntos habitacionais Benjamin José Cardoso (BJC), César Santana Filho (CSF) e Floresta quanto à interação social no conjunto e no bairro anterior Viçosa, MG, 2014

\begin{tabular}{l|l|c|c|c|c|c|c}
\hline \multirow{2}{*}{ Interação social } & \multicolumn{2}{c|}{ BJC - \% } & \multicolumn{2}{c}{ CSF - \% } & \multicolumn{2}{c}{ Floresta - \% } \\
\cline { 3 - 9 } \multicolumn{2}{l|}{} & Conjunto & $\begin{array}{c}\text { Bairro } \\
\text { anterior }\end{array}$ & Conjunto & $\begin{array}{c}\text { Bairro } \\
\text { anterior }\end{array}$ & Conjunto & $\begin{array}{c}\text { Bairro } \\
\text { anterior }\end{array}$ \\
\hline \multirow{2}{*}{ Relação com os vizinhos } & Bom / ótimo & 40 & 72 & 50 & 63 & 67 & 80 \\
& Regular & 45 & 18 & 43 & 30 & 27 & 13 \\
\hline \multirow{2}{*}{ Relação com os moradores } & Péssimo / não tem & 15 & 10 & 7 & 7 & 6 & 7 \\
dos bairros vizinhos & Bom / ótimo & 68 & 60 & 42 & 52 & 67 & 67 \\
\hline \multirow{2}{*}{ Espaços de convívio } & Regular & 20 & 23 & 28 & 23 & 10 & 6 \\
\hline Espaços de lazer & Péssimo / não tem & 12 & 17 & 30 & 25 & 23 & 27 \\
para as crianças & Bom & 17 & 62 & 26 & 62 & 45 & 30 \\
\hline
\end{tabular}

Fonte: Resultados da pesquisa. 
As relações dos moradores com vizinhos nos próprios conjuntos foram bem avaliadas pela maioria dos entrevistados, o que não significa que não existam conflitos entre eles. Por outro lado, as relações entre vizinhos eram meIhores nos bairros anteriores do que as estabelecidas no conjunto. Para isso podem concorrer vários fatores, dentre eles o pequeno tempo de moradia no local. Os moradores do conjunto Benjamin José Cardoso são os que estão menos satisfeitos com a interação com os vizinhos no próprio conjunto e que apontam maior discrepância com as interações estabelecidas nos bairros de origem.

Por sua vez, as relações com os moradores dos bairros vizinhos ao conjunto habitacional foram consideradas como "boas" ou "ótimas" tanto na atual situação de moradia quanto na anterior, com exceção dos moradores do conjunto César Santana Filho. 0 bom relacionamento apontado pelos moradores talvez possa ser atribuído ao fato de muitos serem oriundos de bairros não muito distantes do conjunto habitacional.

Esses resultados apontam para a fragilidade dos laços sociais estabelecidos nos conjuntos habitacionais até o momento, mas não permitem outras inferências, já que o tempo de moradia nos conjuntos é muito pequeno e as pessoas residentes são originárias de várias regiões e bairros de Viçosa, o que demandará maior tempo para a constituição de laços afetivos e de relações de pertencimento ao lugar.

As relações de sociabilidade entre os moradores podem ser construídas ou fortalecidas pelos encontros em locais de lazer das crianças ou de convívio dos adultos. Entretanto, esses espaços foram considerados como "ruins" ou "inexistentes" pela maioria dos entrevistados, nos três conjuntos habitacionais. A situação dos espaços de convívio nos bairros de origem é um pouco melhor do que nos conjuntos, exceto no caso do Conjunto Floresta, provavelmente devido à existência de dois salões para festas ou reuniões no condomínio. Já os espaços de lazer para crianças são tão ruins nos bairros de origem quanto nos conjuntos, exceto no caso do conjunto Benjamin José Cardoso, onde sobressai a precariedade desse tipo de espaço. Estes resultados apontam para a falta de espaços que propiciem maior interação social dos moradores.

\section{c) Segregação social}

Nessa dimensão analisaram-se três variáveis que interferem na inserção social das famílias residentes nos conjuntos habitacionais: bairro de origem, profissão do chefe da família e escolaridade (Tabela 3). 
Tabela 3 - Síntese de indicadores sociais das famílias residentes nos conjuntos habitacionais Benjamin José Cardoso (BJC), César Santana Filho (CSF) e Floresta

Viçosa, MG, 2014

\begin{tabular}{l|l|c|r|r}
\hline \multicolumn{2}{c|}{ Segregação social } & BJC - \% & CSF - \% & Floresta - \% \\
\hline \multirow{3}{*}{ Bairro de origem* } & Nova Viçosa & 15,1 & - & - \\
& Santa Clara & 11,1 & 19,5 & - \\
& Santo Antônio & - & 10,8 & 13,8 \\
& Zona rural & 1,6 & 4,9 & - \\
\hline \multirow{2}{*}{ Profissão do chefe de família* } & Diarista + Doméstica & 55,3 & 36,9 & 45,3 \\
& Do lar & 11,4 & 15,6 & 16,9 \\
& Outras profissões & 33,3 & 47,5 & 37,8 \\
\hline Escolaridade** & Ensino Fundamental & 64,1 & 65,6 & 60,8 \\
\hline
\end{tabular}

Obs.: * Foram incluídos os bairros e as profissões com percentual maior ou igual a $10 \%$.

** Foi incluído o item de maior ocorrência.

Fonte: Resultados da pesquisa.

Os indicadores de endereço (local de moradia), profissão e escolaridade são representativos da vulnerabilidade social das famílias residentes nos conjuntos habitacionais. 0 endereço carrega consigo o estigma da localização no espaço urbano, na medida em que o espaço físico expressa a realidade social dos seus moradores. Os dados referentes aos bairros de origem dos moradores dos conjuntos habitacionais indicaram uma grande gama de localizações, inclusive na área rural, mas na maioria são bairros ocupados por população de renda baixa ou média-baixa.

No conjunto Benjamin José Cardoso predominaram famílias vindas do Bairro Nova Viçosa, também considerado bairro periférico e de baixa renda, e dos "Predinhos dos Araújos", conjunto de edifícios que foram invadidos no Bairro Santa Clara e cujas condições de moradia eram muito precárias. No conjunto César Santana Filho, predominaram famílias vindas do Bairro Santa Clara - o restante dos moradores dos "Predinhos dos Araújos" - e do Bairro Santo Antônio, considerado bairro de renda média-baixa. No condomínio Floresta, grande parte das famílias também veio do Bairro Santo Antônio.

Conclui-se, inicialmente, que as pessoas que residem nos conjuntos habitacionais têm origens diferentes e, portanto, podem ser depositários de costumes, crenças e valores culturais distintos, o que os caracterizaria como um grupo social não homogêneo (embora seja homogêneo em termos de renda), fato que pode interferir nas relações sociais desenvolvidas no espaço de morar. Apesar disso, a maioria dos moradores indicou boas relações de convivência com os vizinhos. Conclui-se, também, pela grande mobilidade intraurbana gerada pela construção dos conjuntos do PMCMV, já que os beneficiários são oriundos de várias partes do município. 
A baixa qualificação e a baixa escolaridade dos residentes nos três conjuntos habitacionais contribuem para o perfil profissional dos chefes de família, constituído na maioria por diaristas, domésticas, trabalhadoras do lar e prestadores de serviços em geral, cuja baixa remuneração contribui para perpetuar a condição de baixos salários e de vulnerabilidade social.

\section{d) Segregação espacial}

A segregação espacial foi avaliada a partir das condições de infraestrutura urbana e de acesso ao trabalho e aos equipamentos urbanos de saúde, educação e lazer (Tabelas 4 e 5).
As condições de acesso aos conjuntos habitacionais e aos equipamentos urbanos de saúde, educação e lazer são consideradas piores na situação atual de moradia do que no caso dos bairros de origem. Apenas no conjunto Floresta o acesso ao local de trabalho foi considerado melhor do que era anteriormente.

As más condições de acesso e, portanto, de mobilidade urbana, potencializam a segregação social e espacial dos moradores.

Da mesma forma que ocorre com as condições de acesso, a maioria dos serviços de infraestrutura urbana foi considerada como em piores condições nos conjuntos habitacionais do que nos bairros de origem (Tabela 5).

Tabela 4 - Percepção dos moradores dos conjuntos habitacionais Benjamin José Cardoso (BJC), César Santana Filho (CSF) e Floresta quanto às condições de acesso aos equipamentos urbanos e ao local de trabalho no conjunto e no bairro anterior Viçosa, MG, 2014

\begin{tabular}{l|l|c|c|c|c|c|c}
\hline \multicolumn{2}{c}{$\begin{array}{c}\text { Condições de acesso a equipamentos } \\
\text { urbanos e ao trabalho }\end{array}$} & \multicolumn{2}{c|}{ BJC - \% } & \multicolumn{2}{c}{ CSF - \% } & \multicolumn{2}{c}{ Floresta - \% } \\
\cline { 3 - 8 } \multicolumn{2}{c|}{} & Conjunto & $\begin{array}{c}\text { Bairro } \\
\text { anterior }\end{array}$ & Conjunto & $\begin{array}{c}\text { Bairro } \\
\text { anterior }\end{array}$ & Conjunto & $\begin{array}{c}\text { Bairro } \\
\text { anterior }\end{array}$ \\
\hline \multirow{2}{*}{ Acesso ao local de moradia } & Bom & 22,5 & 87,2 & 28,2 & 92,3 & 60,0 & 76,7 \\
& Ruim & 77,5 & 12,8 & 72,4 & 7,7 & 40,0 & 23,3 \\
\hline \multirow{2}{*}{ Acesso ao trabalho } & Bom & 35,3 & 93,6 & 38,9 & 94,4 & 51,5 & 35,2 \\
& Ruim & 64,5 & 6,4 & 61,1 & 5,6 & 48,5 & 64,8 \\
\hline \multirow{2}{*}{ Acesso à escola } & Bom & 53,0 & 97,0 & 60,0 & 85,0 & 48,0 & 96,0 \\
& Ruim & 47,0 & 3,0 & 40,0 & 15,0 & 52,0 & 4,0 \\
\hline \multirow{2}{*}{ Acesso à creche } & Bom & 35,0 & 93,0 & 39,0 & 68,0 & 43,0 & 93,0 \\
& Ruim & 65,0 & 0,0 & 52,0 & 16,0 & 57,0 & 7,0 \\
\hline \multirow{2}{*}{ Acesso à Unidade Básica de Saúde } & Não tem & 0,0 & 7,0 & 9,0 & 16,0 & 0,0 & 0,0 \\
\hline \multirow{2}{*}{ Acesso aos espaços de lazer } & Bom & 43,2 & 92,3 & 30,8 & 92,5 & 56,7 & 90,0 \\
& Ruim & 56,8 & 7,7 & 69,2 & 7,5 & 43,3 & 10,0 \\
\hline
\end{tabular}

Fonte: Resultados da pesquisa. 
Tabela 5 - Percepção dos moradores dos conjuntos habitacionais Benjamin José Cardoso (BJC), César Santana Filho (CSF) e Floresta quanto à infraestrutura urbana no conjunto e no bairro anterior Viçosa, MG, 2014

\begin{tabular}{|c|c|c|c|c|c|c|c|}
\hline & & BJC & & CSF & & Flores & $-\%$ \\
\hline Infraestrutura u & & Comiunto & Bairro & Coniunto & Bairro & Coniunto & Bairro \\
\hline Calcamento dac viac internac & Bom & 90,0 & 92,5 & 75,0 & 90,0 & 63,3 & 93,0 \\
\hline Callgalineritu uas vias illterinas & Ruim & 10,0 & 7,5 & 25,0 & 10,0 & 36,7 & 7,0 \\
\hline & Bom & 72,5 & 90,0 & 49,0 & 87,0 & 73,0 & 83,0 \\
\hline Drenagem pluvial & Ruim & 27,5 & 10,0 & 46,0 & 10,0 & 27,0 & 17,0 \\
\hline & Não tem & 0,0 & 0,0 & 5,0 & 3,0 & 0,0 & 0,0 \\
\hline Ahastecimento de áqua & Bom & 80,0 & 80,0 & 100,0 & 80,0 & 100,0 & 100,0 \\
\hline Anastecintentu ue ayua & Ruim & 20,0 & 20,0 & 0,0 & 20,0 & 0,0 & 0,0 \\
\hline Fsantamento sanitário & Bom & 85,0 & 87,5 & 80,0 & 77,5 & 100,0 & 93,3 \\
\hline L & Ruim & 15,0 & 12,5 & 20,0 & 22,5 & 0,0 & 6,7 \\
\hline & Bom & 55,0 & 95,0 & 50,0 & 92,0 & 77,0 & 97,0 \\
\hline Iluminação pública & Ruim & 45,0 & 5,0 & 48,0 & 8,0 & 23,0 & 3,0 \\
\hline & Não tem & 0,0 & 0,0 & 2,0 & 0,0 & 0,0 & 0,0 \\
\hline Coleta de lixo & Bom & 55,0 & 92,5 & 64,0 & 97,0 & 50,0 & 90,0 \\
\hline 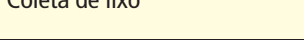 & Ruim & 45,0 & 7,5 & 36,0 & 3,0 & 50,0 & 10,0 \\
\hline & Bom & 92,5 & 95,0 & 52,0 & 97,0 & 50,0 & 90,0 \\
\hline Serviço de Correio & Ruim & 7,5 & 5,0 & 40,0 & 0,0 & 50,0 & 10,0 \\
\hline & Não tem & 0,0 & 0,0 & 8,0 & 3,0 & 0,0 & 0,0 \\
\hline & Bom & 13,0 & 97,0 & 10,0 & 90,0 & 73,0 & 87,0 \\
\hline Telefonia móvel & Ruim & 87,0 & 3,0 & 83,0 & 3,0 & 17,0 & 3,0 \\
\hline & Não tem & 0,0 & 0,0 & 7,0 & 7,0 & 10,0 & 10,0 \\
\hline & Bom & 0,0 & - & 0,0 & - & 27,6 & 13,8 \\
\hline Telefonia fixa* & Ruim & 0,0 & - & 0,0 & - & 72,4 & 86,2 \\
\hline & Não tem & 100,0 & - & 100,0 & - & 0,0 & 0,0 \\
\hline & Bom & 28,2 & 95,0 & 47,5 & 89,7 & 63,0 & 83,0 \\
\hline Acesso ao transporte coletivo & Ruim & 71,8 & 5,0 & 52,5 & 10,3 & 37,0 & 10,0 \\
\hline & Não tem & 0,0 & 0,0 & 0,0 & 0,0 & 0,0 & 7,0 \\
\hline
\end{tabular}

Fonte: Resultados da pesquisa.

Os serviços de drenagem pluvial, iluminação pública, coleta de lixo, correio, telefonia móvel e transporte coletivo foram considerados piores nos três conjuntos habitacionais. Os problemas de drenagem pluvial ocorrem no espaço interno dos empreendimentos, embora haja rede de drenagem com bocas de lobo; a pior situação é encontrada no conjunto César Santana Filho, por causa de uma canaleta para escoamento de água das chuvas que passa nos fundos das residências e que costuma ficar sem limpeza, gerando mau cheiro. Não foi implantada rede de telefonia fixa nos conjuntos Benjamin José Cardoso e César Santana 
Filho, e a ineficácia do sinal de celular é uma grande reclamação dos moradores. No caso da iluminação pública, a insatisfação se deve às vias principais de acesso e não à iluminação no interior dos conjuntos. 0 serviço de lixo é considerado pior devido à menor frequência da coleta durante a semana. De modo semelhante, há poucos horários de ônibus durante o dia, 0 que é motivo de reclamação por parte de muitos moradores.

Alguns serviços de infraestrutura foram considerados melhores do que nos bairros anteriores. Isso foi observado especialmente no conjunto Floresta, em relação aos itens: acesso ao trabalho e aos espaços de convívio, infraestrutura de esgoto, telefonia móvel e fixa, embora essa última seja muito pouco utilizada, tanto no conjunto quanto nos bairros de origem. No conjunto César Santana Filho, o único serviço considerado de melhor qualidade do que nos bairros de moradia anterior é o abastecimento de água. Os serviços de água e esgoto foram avaliados como bons tanto nos conjuntos quanto nos bairros de origem; de fato, a cobertura da autarquia responsável pela prestação do serviço (SAAE - Serviço Autônomo de Água e Esgoto) é muito ampla no município.

\section{e) Percepção dos moradores quanto à moradia}

Por fim, analisou-se a percepção dos moradores quanto às condições de moradia no conjunto comparativamente aos bairros de origem (Tabela 6).

A percepção dos moradores quanto à nova moradia é melhor do que quanto às condições de infraestrutura e de acesso aos equipamentos urbanos e, também, melhor quando comparado às condições de moradia anteriores. Isso pode ser interpretado como satisfação em relação ao produto (casa ou apartamento) entregue pelo PMCMV ou pode significar que os beneficiários moravam em condições precárias. 0 banheiro e o número de quartos, por exemplo, foram considerados como mais adequados no caso dos conjuntos habitacionais do

Tabela 6 - Percepção dos moradores dos conjuntos habitacionais

Benjamin José Cardoso (BJC), César Santana Filho (CSF) e Floresta quanto às características da moradia no conjunto e no bairro anterior Viçosa, MG, 2014

\begin{tabular}{l|l|c|c|c|c|c|c}
\hline \multirow{2}{*}{\multicolumn{2}{c|}{ Condição da moradia }} & \multicolumn{2}{c|}{ BJC - \% } & \multicolumn{2}{c|}{ CSF - \% } & \multicolumn{2}{c}{ Floresta - \% } \\
\cline { 3 - 8 } \multicolumn{2}{l|}{ Adequado } & Conjunto & $\begin{array}{c}\text { Bairro } \\
\text { anterior }\end{array}$ & Conjunto & $\begin{array}{c}\text { Bairro } \\
\text { anterior }\end{array}$ & Conjunto & $\begin{array}{c}\text { Bairro } \\
\text { anterior }\end{array}$ \\
\hline \multirow{3}{*}{} & Número de quartos & 52,5 & 70,0 & 87,5 & 45,0 & 80,0 & 56,7 \\
& Banheiro & 77,5 & 75,0 & 85,0 & 50,0 & 100,0 & 82,1 \\
& Tamanho da cozinha & 10,0 & 90,0 & 20,0 & 62,5 & 30,0 & 82,8 \\
& Tamanho da área de serviço & 20,0 & 30,0 & 57,9 & 71,4 & 17,2 & 82,8 \\
\hline \multirow{2}{*}{ Inadequado } & Espaço para refeições no conjunto & 22,8 & - & 31,6 & - & 21,1 & - \\
& habitacional & & & & & & \\
\hline
\end{tabular}

Fonte: Resultados da pesquisa. 
Tabela 7 - Satisfação dos moradores dos conjuntos habitacionais

Benjamin José Cardoso (BJC), César Santana Filho (CSF) e Floresta com a moradia e com o bairro anterior

Viçosa, MG, 2014

\begin{tabular}{|c|c|c|c|c|}
\hline \multicolumn{2}{|c|}{ Relação com o bairro e com a moradia } & BJC $-\%$ & CSF $-\%$ & Floresta - \% \\
\hline $\begin{array}{c}\text { Relação com } \\
\text { o bairro anterior }\end{array}$ & $\begin{array}{l}\text { Muito bom / Bom } \\
\text { Razoável } \\
\text { Não gostava }\end{array}$ & $\begin{array}{r}82,5 \\
7,5 \\
10,0\end{array}$ & $\begin{array}{r}87,5 \\
12,5 \\
0\end{array}$ & $\begin{array}{r}83,3 \\
13,3 \\
3,3\end{array}$ \\
\hline $\begin{array}{l}\text { Relação com } \\
\text { a moradia }\end{array}$ & $\begin{array}{l}\text { Gostava mais da moradia anterior do que da atual } \\
\text { por causa dos vizinhos } \\
\text { Gostava mais da moradia anterior do que da atual } \\
\text { por causa do bairro } \\
\text { Gostava mais da moradia anterior do que da atual } \\
\text { porque não gosta de morar em condomínio } \\
\text { A moradia anterior era muito adequada às } \\
\text { necessidades da família } \\
\text { Gosta mais da moradia atual } \\
\text { Não se manifestou }\end{array}$ & $\begin{array}{r}4,5 \\
6,8 \\
- \\
29,5 \\
54,5 \\
4,7\end{array}$ & $\begin{array}{r}7,14 \\
8,93 \\
- \\
17,9 \\
57,1 \\
8,9\end{array}$ & $\begin{array}{r}6,3 \\
3,1 \\
3,1 \\
34,4 \\
46,9 \\
6,2\end{array}$ \\
\hline
\end{tabular}

Fonte: Resultados da pesquisa.

que nas moradias anteriores, sobretudo para os entrevistados dos conjuntos César Santana Filho e Floresta. Uma queixa constante é a pequena dimensão da cozinha e da área de serviço e a falta de espaço para refeições.

A satisfação com a moradia anterior, manifestada por $40,8 \%$ dos entrevistados no conjunto Benjamin José Cardoso, 33,9\% no conjunto César Santana Filho e $46,9 \%$ no conjunto Floresta, deve-se menos às características da casa e mais às condições do bairro, nelas incluindo-se não só as próprias características do local, mas também as relações de solidariedade entre vizinhos (Tabela 7).

De posse dos dados tabulados e retomando o método proposto por Ramos e Sá (2002) para medir a eficácia social de uma política, apresenta-se no Quadro 1 a síntese comparativa das condições de moradia existentes nos bairros de origem versus a condição vivenciada nos conjuntos habitacionais.

A percepção dos moradores em relação à interação social no conjunto e no bairro de origem é bastante variável, como se observa no Quadro 1. Mesmo assim, foi avaliada como "boa" ou "regular" pela maioria dos entrevistados, com mostrado anteriormente.

Apenas no conjunto Floresta o acesso ao local de trabalho foi considerado melhor do que era anteriormente. Todos os demais indicadores (acesso aos próprios empreendimentos, às Unidades Básicas de Saúde, escolas, creches e espaços de convívio/lazer) foram muito mal avaliados pelos entrevistados. As 
Quadro 1 - Comparação das condições de acesso, infraestrutura e moradia nos conjuntos habitacionais Benjamin José Cardoso (BJC), César Santana Filho (CSF) e Floresta em relação ao bairro de origem dos moradores, segundo a percepção dos entrevistados Viçosa, MG, 2014

\begin{tabular}{|c|c|c|c|}
\hline $\begin{array}{l}\text { Condição do conjunto habitacional } \\
\text { em relação ao local de moradia anterior }\end{array}$ & BJC - \% & CSF $-\%$ & Floresta - \% \\
\hline \multicolumn{4}{|l|}{ Interação social } \\
\hline $\begin{array}{l}\text { Relação com os vizinhos } \\
\text { Relação com os moradores dos bairros vizinhos } \\
\text { Espaços de convívio } \\
\text { Espaços de lazer para as crianças }\end{array}$ & $\begin{array}{l}\text { Pior } \\
\text { Melhor } \\
\text { Pior } \\
\text { Pior }\end{array}$ & $\begin{array}{l}\text { Pior } \\
\text { Pior } \\
\text { Pior } \\
\text { Semelhante }\end{array}$ & $\begin{array}{l}\text { Pior } \\
\text { Semelhante } \\
\text { Melhor } \\
\text { Semelhante }\end{array}$ \\
\hline \multicolumn{4}{|l|}{ Condições de acesso } \\
\hline $\begin{array}{l}\text { Condições de acesso ao conjunto } \\
\text { Acesso ao trabalho } \\
\text { Acesso à escola } \\
\text { Acesso à creche } \\
\text { Acesso à Unidade Básica de Saúde } \\
\text { Acesso aos espaços de lazer }\end{array}$ & $\begin{array}{l}\text { Pior } \\
\text { Pior } \\
\text { Pior } \\
\text { Pior } \\
\text { Pior } \\
\text { Pior }\end{array}$ & $\begin{array}{l}\text { Pior } \\
\text { Pior } \\
\text { Pior } \\
\text { Pior } \\
\text { Pior } \\
\text { Pior }\end{array}$ & $\begin{array}{l}\text { Pior } \\
\text { Melhor } \\
\text { Pior } \\
\text { Pior } \\
\text { Pior } \\
\text { Pior }\end{array}$ \\
\hline \multicolumn{4}{|l|}{ Infraestrutura urbana } \\
\hline $\begin{array}{l}\text { Calçamento das vias no interior do conjunto } \\
\text { Drenagem pluvial } \\
\text { Serviço de abastecimento de água } \\
\text { Esgotamento sanitário } \\
\text { lluminação pública } \\
\text { Coleta de lixo } \\
\text { Correio } \\
\text { Telefonia móvel } \\
\text { Telefonia fixa } \\
\text { Acesso ao transporte coletivo }\end{array}$ & $\begin{array}{l}\text { Semelhante } \\
\text { Pior } \\
\text { lgual } \\
\text { Semelhante } \\
\text { Pior } \\
\text { Pior } \\
\text { Semelhante } \\
\text { Muito pior } \\
\text { Não tem } \\
\text { Pior }\end{array}$ & $\begin{array}{l}\text { Pior } \\
\text { Pior } \\
\text { Melhor } \\
\text { Semelhante } \\
\text { Pior } \\
\text { Pior } \\
\text { Pior } \\
\text { Muito pior } \\
\text { Não tem } \\
\text { Pior }\end{array}$ & $\begin{array}{l}\text { Pior } \\
\text { Pior } \\
\text { Igual } \\
\text { Melhor } \\
\text { Pior } \\
\text { Pior } \\
\text { Pior } \\
\text { Melhor } \\
\text { Melhor } \\
\text { Pior }\end{array}$ \\
\hline \multicolumn{4}{|l|}{ Condições da moradia atual } \\
\hline $\begin{array}{l}\text { Número de quartos } \\
\text { Banheiro } \\
\text { Tamanho da cozinha } \\
\text { Tamanho da área de serviço } \\
\text { Espaço para refeições } \\
\text { Adequação da moradia atual em relação à anterior }\end{array}$ & $\begin{array}{l}\text { Pior } \\
\text { Semelhante } \\
\text { Muito pior } \\
\text { Semelhante } \\
\text { Não tem } \\
\text { Melhor }\end{array}$ & $\begin{array}{l}\text { Melhor } \\
\text { Melhor } \\
\text { Pior } \\
\text { Pior } \\
\text { Não tem } \\
\text { Melhor }\end{array}$ & $\begin{array}{l}\text { Melhor } \\
\text { Melhor } \\
\text { Pior } \\
\text { Pior } \\
\text { Não tem } \\
\text { Melhor }\end{array}$ \\
\hline
\end{tabular}

Fonte: Resultados da pesquisa.

más condições de acesso e, portanto, de mobilidade urbana potencializam a segregação social e espacial dos moradores desses conjuntos habitacionais e, portanto, denotam pouca eficácia social.
Quanto à infraestrutura, as condições de drenagem das águas pluviais, iluminação pública, coleta de lixo e acesso ao transporte coletivo foram consideradas de pior qualidade em todos os três conjuntos habitacionais. 
A telefonia móvel e a telefonia fixa só foram melhor avaliadas no conjunto habitacional Floresta. A telefonia fixa inexiste nos conjuntos Benjamin José Cardoso e César Santana Filho e, embora no conjunto Floresta tenha sido avaliada como melhor do que nos bairros de origem, trata-se de um serviço pouco utilizado pelos moradores, que preferem utilizar o telefone celular. Por outro lado, a ineficácia do sinal de celular nos conjuntos César Santana Filho e Benjamin José Cardoso agrava as condições de segregação espacial impostas pela localização periférica dos moradores e os torna ainda mais isolados do restante da cidade.

Os serviços de abastecimento de água e esgotamento sanitário foram os únicos bem avaliados pelos entrevistados, tanto nos conjuntos habitacionais quanto nos bairros anteriores.

No caso da unidade habitacional propriamente dita, os resultados se invertem, já que, na percepção dos entrevistados, a moradia anterior era pior do que a atual. São três os aspectos considerados negativos na moradia atual: o tamanho da cozinha, a falta de um espaço para refeições e o tamanho da área de serviço.

\section{Conclusões}

Este artigo teve como objetivo empreender uma reflexão sobre a eficácia social dos conjuntos habitacionais Benjamim José Cardoso, César Santana Filho e Floresta implantados em Viçosa-MG, por meio do Programa Minha Casa Minha Vida (PMCMV) para a população com renda familiar igual ou inferior a três salários mínimos.
Os resultados encontrados indicam que nenhum dos empreendimentos pode ser considerado eficaz do ponto de vista social. Praticamente todas condições foram consideradas piores do que aquelas vivenciadas pelos entrevistados nos seus bairros de moradia anterior. A situação é mais grave no caso da infraestrutura urbana e das condições de acesso aos próprios empreendimentos, aos locais de trabalho e aos equipamentos urbanos de saúde, educação (escolas e creches) e lazer.

A precariedade dos acessos aos conjuntos (condições das vias principais de acesso, dificuldade de acesso ao transporte coletivo, aos locais de trabalho e aos equipamentos de educação, saúde e lazer) constituem fatores que segregam espacialmente a população moradora nos conjuntos habitacionais e, portanto, também são indicativos de falta de eficácia social. Da mesma forma, a má qualidade da infraestrutura urbana, sobretudo nos acessos aos conjuntos habitacionais (como falta de calçadas, pavimentação inadequada, falta de pavimentação e de iluminação pública) isolam os moradores do restante da cidade e também reforçam a segregação social e espacial.

Tais carências relativas à má localização dos empreendimentos não são distintas das apontadas pelos estudos sobre o PMCMV nas cidades médias ou nas metrópoles.

Por sua vez, as más condições dos serviços urbanos no interior dos conjuntos (drenagem pluvial, falta de sinal de celular, falta de telefonia fixa, calçamento, etc.) denotam um desrespeito do poder público pelos moradores, que são tratados como cidadãos de "segunda categoria". 
0 provimento da habitação de interesse social pelo poder público municipal limita-se à provisão da unidade habitacional, desvinculada de uma política urbana que vise à localização adequada das moradias destinadas à população de baixa renda. Essa visão torna-se a principal responsável pela falta de eficácia social dos empreendimentos construídos em Viçosa. Ainda que os moradores estejam mais satisfeitos com as casas atuais do que com as anteriores, entende-se que a habitação - que abrange todos os elementos que circunscrevem a vida cotidiana dos moradores e, portanto, extrapola a mera unidade habitacional - não atende aos critérios de eficácia social.
Conclui-se, portanto, pela ineficácia social dos conjuntos habitacionais do PMCMV em Viçosa, sobretudo devido à concentração de uma população socialmente homogênea e numa área desprovida de condições adequadas de infraestrutura urbana e de acesso aos equipamentos de saúde, educação e lazer, fatores que estão associados à localização desses empreendimentos.

Cientes de que os resultados desse estudo não podem ser generalizados, longe de esgotar o tema, espera-se com essas reflexões ter lançado luz sobre algumas questões que também conformam o debate sobre as novas formas de produção habitacional nas pequenas cidades brasileiras.

\section{Aline Werneck Barbosa Carvalho}

Universidade Federal de Viçosa, Departamento de Arquitetura e Urbanismo. Viçosa/MG, Brasil. alinewbc@gmail.com

\section{Italo Itamar Caixeiro Stephan}

Universidade Federal de Viçosa, Departamento de Arquitetura e Urbanismo. Viçosa/MG, Brasil. stephan@ufv.br

\section{Notas}

$\left({ }^{*}\right)$ Os resultados apresentados neste artigo são frutos da pesquisa denominada "Eficácia Social do Programa Minha Casa Minha Vida em Viçosa-MG", financiada pela Fundação de Amparo à Pesquisa do Estado de Minas Gerais - Fapemig.

(1) Dados obtidos no site da Caixa Econômica Federal (Caixa). Disponível em: http://www20.caixa. gov.br/Paginas/Noticias/Noticia/Default.aspx?newsID=1011. Acesso em: 22 jan 2015.

(2) Se considerarmos como pequenas cidades aquelas cujos municípios têm população inferior a 100.000 habitantes, isso equivale a $94,6 \%$ dos municípios brasileiros, segundo dados Instituto Brasileiro de Geografia e Estatística (IBGE), em estimativa de 2014.

(3) Costa e Castanhar (2003) enumeram vários critérios de avaliação: eficiência, eficácia, impacto (efetividade), sustentabilidade, análise custo-efetividade, satisfação do usuário e equidade. 
(4) Segundo dados da publicação "Retrato Social de Viçosa IV", em 2010 a população flutuante de Viçosa girava em torno de 15.000 pessoas e era formada basicamente por estudantes (Cruz, 2012).

(5) Lei n. 1383/2000 e Lei n. 1420/2000, respectivamente.

\section{REFERÊNCIAS}

AGUILLAR, M. J. e ANDER-EGG, E. (1994). Avaliação de serviços e programas sociais.Petrópolis/RJ, Vozes.

ARANTES, P. F. e FIX, M. (2009). Como o governo Lula pretende resolver o problema da habitação. Alguns comentários sobre o pacote habitacional Minha Casa, Minha Vida. Correio da Cidadania. Disponível em: http://www.correiocidadania.com.br/index.php?option=com_content\&view=ca tegory\&layout=blog\&id=66\&ltemid=171. Acesso em: 20 jun 2012.

BONDUKI, N. (2009). Do Projeto Moradia ao Programa Minha Casa Minha Vida. Teoria e Debate. São Paulo, n. 82, pp. 8-14.

BRASIL (2005). Política Nacional de Habitação. Brasília-DF, Caderno MCidades, n. 4. (2009). Lei 11.977, de 07 de julho de 2009. Dispõe sobre o Programa Minha Casa, Minha Vida. Brasília- DF, Diário Oficial da União.

(2011). Lei 12.424, de 16 de junho. Disponível em: http://www.planalto.gov.br/ccivil_03/_ ato2011-2014/2011/lei/l12424.htm. Acesso em: 10 set 2014.

BUONFIGLIO, L. V. e BASTOS, R. D. (2011). O lugar das políticas de habitação popular nas cidades brasileiras. Disponível em: http://xiisimpurb2011.com.br/app/web/arq/trabalhos/4071c402a43 c458597efe06f896757f7.pdf. Acesso em: 12 jun 2012.

CARDOSO, A. L. (org.) (2013). O PMCMV e seus efeitos territoriais. Rio de Janeiro, Letra Capital.

CARDOSO, A. e ARAGÃO, T. A. (2011). "A reestruturação do setor imobiliário e o Programa Minha Casa Minha Vida". In: MENDONÇA, J. G. e COSTA, H. S. de M. (orgs.). Estado e capital imobiliário: convergências atuais na produção do espaço urbano brasileiro. Belo Horizonte, C/ Arte.

CARVALHO, A. W. B.; STEPHAN, I. I. C. e GUEDES, M. M. (2015). Avaliação da eficácia social do Programa Minha Casa, Minha Vida em Viçosa, MG. Relatório de Pesquisa (Iniciação Científica). Viçosa-MG, Universidade Federal de Viçosa.

CHIECHELSKI, P. C. S. (2005). Avaliação de programas sociais: abordagens quantitativas e suas limitações. Revista Virtual Textos \& Contextos, n. 4, ano IV. Disponível em: ///C:/Users/Cliente/ Downloads/1006-3670-2-PB.pdf. Acesso em: 29 maio 2015.

COSTA, F. L. e CASTANHAR, J. C. (2003). Avaliação de programas públicos: desafios conceituais e metodológicos. RAP-Revista de Administração Pública. Rio de Janeiro, v. 37, n. 5, pp. 969-92.

COTTA, T. C. (1998). Metodologias de avaliação de programas e projetos sociais: análise de resultados e de impacto. RSP-Revista do Serviço Público. Brasília-DF, ano 49, n. 2, pp. 103-124. 
CRUZ, T. A. (coord.) (2012). Retrato social de Viçosa IV. Viçosa-MG, Census.

DENALDI, R. (2012). Política habitacional e urbana: avanços e impasses. Disponível em: http:// www.phdu.comuv.com/attachments/article/18/Pol\%C3\%ADtica\%20Habitacional\%20e\%20 Urbana\%20avan\%C3\%A7os\%20e\%20impasses\%20\%20-20Rosana\%20Denaldi.pdf. Acesso em: 29 set 2012.

FAGUNDES, H. e MOURA, A. B. (2009). Avaliação de programas e políticas públicas. Revista Textos \& Contextos. Porto Alegre, v. 8, n. 1, pp. 89-103.

HIRATA, F. (2011). Minha casa, minha vida: política habitacional e de geração de emprego ou aprofundamento da segregação urbana? Revista Aurora, v. 3, n. 4. Disponível em: http://www2. marilia.unesp.br/revistas/index.php/aurora/article/view/1202. Acesso em: 20 jun 2012.

JANNUZZI, P. M. (2002). Considerações sobre o uso, mau uso e abuso dos indicadores sociais na formulação e avaliação de políticas públicas municipais. RAP - Revista de Administração Pública. Rio de Janeiro, v. 36, n. 1, pp. 51-72.

KLINTOWITZ, D. C. (2011). Como as políticas habitacionais se inserem nos contextos de reforma do estado? A experiência recente do Brasil. Revista Pensamento \& Realidade. São Paulo, v. 26, n. 3, pp. 101-120.

MARICATO, E. (2009). O “Minha Casa” é um avanço, mas segregação urbana fica intocada. Disponível em: http://cartamaior.com.br/?/Editoria/Politica/O-Minha-Casa-e-um-avanco-mas-segregacaourbana-fica-intocada/4/15160. Acesso em: 27 jun 2009.

(2011). O impasse da política urbana no Brasil. Petrópolis/RJ, Vozes.

MARINHO, A. e FAÇANHA, L. O. (2001). Programas sociais: efetividade, eficiência e eficácia como dimensões operacionais da avaliação. Texto para Discussão - Ipea. Rio de Janeiro, n. 787, pp. 1-22.

MOHR, L. B. (1995). Impact analysis for program evaluation. Londres, Sage Publications.

MONTEIRO, G. T. M. (2002). A avaliação dos impactos sociais dos programas de governo. In: VII CONGRESSO INTERNACIONAL DEL CLAD SOBRE LA REFORMA DEL ESTADO Y DE LA ADMINISTRACIÓN PÚBLICA. Anais. Lisboa, Portugal, pp. 8-11.

PAULA, K. de A. (2013). A produção do espaço urbano vertical na área central de Viçosa, no período 1980-2012. Dissertação de Mestrado. Viçosa, Universidade Federal de Viçosa.

PENALVA, A. M. S. e DUARTE, S. M. (2010). Política habitacional no Brasil: uma nova abordagem para um velho problema. RFD- Revista da Faculdade de Direito da UERJ. Rio de Janeiro, v. 1, n. 18, pp. 1-29.

RAMOS, M. H. R. e SÁ, M. E. R. (2002). “Avaliação da política de habitação popular segundo critérios de eficácia societal”. In: RAMOS, M. H. R. (org.). Metamorfoses sociais e políticas urbanas. Rio de Janeiro, DP\&A.

ROLNIK, R. e KLINK, J. (2011). Crescimento econômico e desenvolvimento urbano:por que nossas cidades continuam tão precárias? Novos Estudos-Cebrap. São Paulo, n. 89, pp. 89-109.

SHIMBO, L. Z. (2011). "Empresas construtoras, capital financeiro e a constituição da habitação de mercado". In: MENDONÇA, J. G. e COSTA, H. S. M. (orgs.). Estado e capital imobiliário: convergências atuais na produção do espaço urbano brasileiro. Belo Horizonte, C/Arte. 
SILVA, B. F. e SILVA, R. D. (2013)."As novas formas de provisão de moradia e seus impactos na reconfiguração socioespacial do aglomerado Sarandi-Maringá entre 2009 e 2011". In: CARDOSO, A. L. (org.). O PMCMV e seus efeitos territoriais. Rio de Janeiro, Letra Capital.

TREVISAN, A. P. e VAN BELLEN, H. M. (2008). Avaliação de políticas públicas: uma revisão teórica de um campo em construção. RAP - Revista de Administração Pública. Rio de Janeiro, v. 42, n. 3, pp. 529-550.

VALENÇA, M. M. e BONATES, M. F. (2010). The trajectory of social housing policy in Brazil: from the National Housing Bank to the Ministry of the Cities. Habitat International, v. 34, n. 2, pp. 165-173.

\section{Agradecimentos}

Fundação de Amparo à Pesquisa do Estado de Minas Gerais, pelo apoio.

Marina Galatro Menta Guedes, estudante de Arquitetura e Urbanismo do Departamento de Arquitetura e Urbanismo da Universidade Federal de Viçosa e bolsista Fapemig, que colaborou com os autores na elaboração do artigo.

Texto recebido em 31/maio/2015

Texto aprovado em 11/set/2015 
